\begin{tabular}{|c|c|c|}
\hline & $\begin{array}{c}\text { Mobilya ve Ahşap Malzeme Araştırmaları Dergisi } \\
\text { Furniture and Wooden Material Research Journal } \\
\text { Araştırma Makalesi - Research Article } \quad 2018-1(2), 103-108\end{array}$
\end{tabular}

\title{
Yonga levha üretiminde pirinç kavuzu kullanımının yüzey pürüzlülüğü üzerine etkisi
}

\author{
Fatih Şahin ${ }^{1}$, Emre Birinci $^{2}$, Alperen Kaymakc1 ${ }^{3 *}$
}

\section{$\ddot{\mathbf{O} z}$}

Dünyadaki hammadde yetersizliği ve çevresel baskılardan dolayı farklı lignoselülozik hammadde kaynakları arayışı giderek artmaktadır. Bu kapsamda, orman ürünleri endüstrisi fabrika atıkları, odun unu/talaşı, orman kesim atıkları, yıllık bitki atıkları vb. lignoselülozik malzemelerin kullanım olanakları hakkında çeşitli araştırmalar yapılmaktadır. Türkiye'de buğday, pamuk, ayçiçeği, pirinç vb. ürünler en çok üretilen tarımsal ürünler arasında yer almaktadır. Bu ürünlerin üretimi esnasında ortaya çıkan atıkların çoğu yasak olmasına rağmen üreticiler tarafından tarlalarda yakılarak imha edilmektedir. Bu çalışma kapsamında \%0, 10, 20 ve 30 oranlarında pirinç kavuzları kullanılarak üre formaldehit reçinesi yardımı ile 4 tip yonga levha üretilmiştir. Elde edilen yonga levhaların yüzey pürüzlülüğü parametreleri belirlenmiştir. Araştırma sonuçlarına göre; pirinç kavuzlarının yonga levha üretiminde kullanılmasının yüzey pürüzlülüğünü genel olarak azalttığı tespit edilmiştir. Ayrıca yonga levha içerisinde pirinç kavuzu kullanım oranının artmasına bağlı olarak tüm yüzey pürüzlülüğü parametrelerinin genel olarak azalmış olduğu belirlenmiştir.

Anahtar kelimeler: Yonga levha, pirinç kavuzu, yüzey pürüzlülüğü

\section{The effect of using rice husk in production of particleboard on surface roughness}

\begin{abstract}
Due to lack of raw materials and, environmental concerns in the world, the search for different sources of lignocellulosic raw materials is increasing. In this context, the forest products industry factory wastes, wood flour / wood sawdust, foliage, annual plant waste etc. there are various researches on the use of lignocellulosic materials. In Turkey, wheat, cotton, sunflower, rice etc. the products are among the most-produced agricultural products. Although most of the wastes generated during the production of these products are prohibited, they are destroyed by the producers in the fields by burning. In the scope of this study, 4 types of particleboard were produced with the help of urea formaldehyde resin by using rice husks at $0,10,20$ and $30 \%$ ratios. The surface roughness parameters of the obtained particleboards were determined. According to the results of the research, it was determined that the use of rice husks in the production of particleboard reduced the surface roughness. In addition, it was determined that all surface roughness parameters were decreased due to the increase of the use of rice husks in the particleboard.
\end{abstract}

Keywords: Particleboard, rice husk, surface roughness 


\section{Giriș}

Ahşap malzeme insanlığın ilk çağlarından beri kullanılan ve popülerliği artarak devam eden yenilenebilir bir materyaldir. Son yıllarda ahşap malzemeye olan talebin artması, masif malzemeye alternatif yeni mühendislik malzemelerinin ortaya çıkmasını kaçınılmaz kılmıştır. $\mathrm{Bu}$ gelişmeye paralel olarak yonga levha başta olmak üzere birçok odun esaslı levha ürünü üretilmiştir.

Yonga levha, genellikle lignoselülozik materyallerden elde edilen yonga veya küçük parçaların termoset tutkal ya da uygun bir bağlayıcı ile sıcaklık ve basınç altında preslenmesi sonucu elde edilen bir malzemedir (Akyüz, 2004; Martins ve ark., 2018). Yonga levha üretiminde iğne yapraklı ve yapraklı ağaçların yanı sıra odunsu yapılar barındıran kenevir, şeker kamışı, pamuk sapları, keten, bambu, saman, yer fistığı kabuğu, buğday sapı gibi yıllık bitkilerde kullanılabilmektedir (Mengeloğlu ve Alma, 2002; Çöpür ve ark., 2006).

Y1llk bitki atıkları önemli bir potansiyele sahip olmasına karşın yeterli derecede değerlendirilememektedir. Dünyada yıllık bitkilerin kullanımı konusunda birçok araştırma yapılmıştır (Cooper ve Balatinecz, 1999). Bu tür malzemelerin yonga levha üretimine uygunluğunun araştırılması levha üreticilerinin dikkatini çekeceği düşünülmektedir (Liew ve ark., 2018).

Arkeolojik bulgulara göre yaklaşık 9000 yıl önce Çin'de tüketilmeye başlanan pirinç, sıcak, özellikle bol yağış alan sulak bölgelerde yetiştirilen bir bitkidir. International Grains Council raporlarına göre dünya pirinç üretim miktarı ortalama 600 milyon ton civarındadır. $\mathrm{Bu}$ üretimin en önemli kısmını Çin, Endonezya, Hindistan, Vietnam ve Bangladeş üretmektedir. Bu ülkelerin yıllık pirinç üretim miktarları Çin 143 milyon ton, Hindistan 104 milyon ton, Endonezya 40 milyon ton, Bangladeş 32 milyon ton, Vietnam 30.6 milyon ton ve Tayland 21.3 milyon tondur. TÜIKK verilerine göre Türkiye'de ise y1llık pirinç üretimi 600 bin tondur (Yavuz ve ark., 2016).

Pirinç üretiminde karşılaşılan sorunların başında hasat sonrasında tarlada kalan kavuzların ortadan kaldırılması gelmektedir. Pirinç bitkisinin kavuz/tane oranının fazla olmasından dolayı 1 tonluk pirinç hasadından sonra tarlada yaklaşı 350-400 kg arasında kavuz kalmaktadır. Pirinç kavuzunda yüksek oranda silisyum bulunduğundan dolayı parçalanması güçtür. $\mathrm{Bu}$ nedenle pirinç kavuzları bir sonraki ekime kadar tarlada kendiliğinden çürüyerek ortadan tamamen kalkamamaktadır. Bu sorunu üreticiler yasak olmasına rağmen tarlada kalan pirinç kavuzlarını yakarak bertaraf etmeye çalışmaktadırlar. $\mathrm{Bu}$ durum küresel karbon emisyonunun artmasını sağlamaktadır.Pirinç kavuzunun farklı alanlarda odun hammaddesinin yerine ikame edilmesi hem ülke ekonomisine önemli katkılar sağlayacak hem de küresel karbon emisyonunun azaltılmasına katkıda bulunacaktır (Kayışoğlu ve ark., 2016).

$\mathrm{Bu}$ çalışma kapsamında, yonga levha üretiminde $\% 0,10,20$ ve 30 oranlarında pirinç kavuzu kullanılmıştır. Elde edilen yonga levhaların yüzey pürüzlüğü testleri gerçekleştirilmiştir. 


\section{Materyal ve Metot}

\subsection{Materyal}

Çalışma kapsamında, Kastamonu Entegre AŞ. Kastamonu Yonga Levha Fabrikası'nda $18 \mathrm{~mm}$ kalınlığında, $630 \mathrm{~kg} / \mathrm{m}^{3}$ yoğunluğunda ve $2100 \times 2800 \mathrm{~mm}$ ebatlarında yonga levhalar üretildi. Üretilen bu levhalara çeşitli oranlarda pirinç kavuzu ilave edilerek TS EN 325 (2014) standartlarına uygun olacak şekilde, istenilen boyutlarda örnekler kesildi. Üretim reçetesine ilişkin detaylar Çizelge 1'de gösterilmiştir.

Çizelge 1. Üretilen yonga levhalara eklenen pirinç kavuzu oranı

\begin{tabular}{|c|c|c|}
\hline Gruplar & $\begin{array}{c}\text { Orta Tabakada } \\
(\%)\end{array}$ & $\begin{array}{c}\text { Üst Tabakada } \\
(\%)\end{array}$ \\
\hline A & 0 & 0 \\
\hline B & 10 & 10 \\
\hline C & 20 & 20 \\
\hline D & 30 & 30 \\
\hline
\end{tabular}

\subsection{Metot}

\subsubsection{Yonga Levhaların Üretilmesi}

$\mathrm{Bu}$ araştırmada, deneme levhaları üretiminde yonga levha iş akışına bağlı olarak yongalama, kurutma, eleme, tutkallama, serme, ön presleme, sicak presleme, klimatizasyon, ebatlama, zımparalama ve depolama işlemleri gerçekleştirilmiştir.

Deneme levhalarının üretimi esnasında proses şartlarına bağlı kalınarak, Pinus nigra, Pinus sylvestris L, Pinus brutia, Quercus petraea ve Populus alba odunları karışım halinde kullanılmıştır. Kuru silolardan dozajlanarak alınan $\sim \% 1.0-1.2$ rutubet derecesindeki yongalar/talaşlar ile pirinç kavuzu ayrı ayrı orta ve üst tabaka tutkallama makinalarında pulverize şeklinde püskürtülen ÜF tutkal çözeltisi ile karıştırılmıştır. Deneme levhalarının üretiminde, $1.06 \mathrm{gr} / \mathrm{cm}^{3}$ yoğunluğa sahip amonyum klorürün $\left(\mathrm{NH}_{4} \mathrm{Cl}\right) \% 20$ 'lik sulu çözeltisi kullanılmıştır. Levhaların su alma ve kalınlık artışını azaltmak için katı madde oranı \%60'lık ve yoğunluğu $0.96 \mathrm{gr} / \mathrm{cm}^{3}$ olan beyaz renkli parafin emülsiyonundan yararlanılmıştır.

\subsubsection{Yüzey Pürüzlülüğünün Belirlenmesi}

Test örnekleri 18 x 50 × $50 \mathrm{~mm}$ boyutlarında kesilmiş, 2 hafta süre ile $\% 65 \pm 5$ bağ 1 nem ve $20 \pm 2{ }^{\circ} \mathrm{C}$ sicaklikta hava kurusu rutubet derecesine gelinceye kadar klimatize edilmiştir. Testler Tokyo Seimitsu Accretech Handysurf E-35 B iğne taramalı portatif yüzey ölçüm cihazı ile yapılmıştır. Test örneklerinin yüzey pürüzlülüğü özelliklerini belirlemek için ISO 4287 standardına uygun şekilde ölçümler yapılmıştır. Profil girintileri ile çıkıntıları arasında bulunan merkez çizgisi ortalama pürüzlülük değerleri $(\mathrm{Ra})$, on nokta pürüzlülüğü ortalama değeri $(\mathrm{Rz})$ ve pürüzlülük profili elemanlarının ortalama genişliği (RSm) değerleri ölçülmüştür. Ölçümler oda sıcaklığında, ölçme hızı $0.5 \mathrm{~mm} / \mathrm{sn}$, tarama uzunluğu $12.5 \mathrm{~mm}$ ve sınır dalga boyu, $\lambda c=0.25 \mathrm{~mm}$ olacak şekilde yapılmıştır. Her bir parametredeki bir deney levhası için 10 ölçüm yapılmış ve 10 levha tekrarlı olmak üzere toplam 100 ölçüm yapılmıştır. 


\subsubsection{Verilerin Değerlendirilmesi}

Elde edilen verilerin istatistiksel olarak değerlendirilmesi için IBM SPSS 23.0 paket programından yararlanılmıştır. Çalışmada faktörlerin elde edilen sonuçlar üzerinde anlamlı olup olmadığını belirleyebilmek için basit varyans analizi, anlamlı bulunan faktörler üzerinde de Duncan testi yapılmıştır. Ayrıca 2 saat suda bekleme neticesinde yüzey pürüzlülüğünde meydana gelen farklılıkları belirleyebilmek için eşleştirilmiş $\mathrm{T}$ testi uygulanmıştır.

\section{Bulgular ve Tartışma}

Çeşitli oranlarda pirinç kavuzu kullanılarak üretilen yonga levhaların hava kurusu rutubet hali ve 2 saat suda bekletilmesi sonucunda yüzey pürüzlülügünde meydana gelen değişimlere ilişkin sonuçlar Çizelge 2'de verilmiştir.

Çizelge 2. Hava kurusu ve 2 saat suda bekletilmiş yonga levhaların yüzey pürüzlülük değerlerinin eşleştirilmiş $t$ testi sonuçları

\begin{tabular}{|c|c|c|c|c|c|c|c|}
\hline \multirow{2}{*}{ Gruplar } & \multicolumn{3}{|c|}{ Hava Kurusu Rutubet (HK) } & \multicolumn{3}{|c|}{ 2 Saat Su Alma Sonrası (TY) } \\
\cline { 2 - 7 } & $\begin{array}{c}\mathbf{R a} \\
(\boldsymbol{\mu m})\end{array}$ & $\begin{array}{c}\mathbf{R z} \\
(\boldsymbol{\mu m})\end{array}$ & $\begin{array}{c}\mathbf{R S m} \\
(\boldsymbol{\mu m})\end{array}$ & $\begin{array}{c}\mathbf{R a} \\
(\boldsymbol{\mu m})\end{array}$ & $\begin{array}{c}\mathbf{R z} \\
(\boldsymbol{\mu m})\end{array}$ & $\begin{array}{c}\mathbf{R S m} \\
(\boldsymbol{\mu m})\end{array}$ \\
\hline $\mathbf{A}$ & $4.45 \mathbf{a}^{1}$ & $21.18 \mathbf{a}$ & $120.10 \mathbf{n s}$ & $4.80 \mathbf{a}$ & $22.30 \mathbf{a}$ & $132.38 \mathbf{a}$ \\
& $(0.80)$ & $(4.48)$ & $(25.43)$ & $(1.16)$ & $(5.00)$ & $(28.95)$ \\
\hline $\mathbf{B}$ & $3.62 \mathbf{b}$ & $18.02 \mathbf{b}$ & $113.65 \mathbf{n s}$ & $4.27 \mathbf{b}^{*}$ & $20.03 \mathbf{b}$ & $122.94 \mathbf{a b}$ \\
& $(0.99)$ & $(4.65)$ & $(24.12)$ & $(0.88)$ & $(4.39)$ & $(25.08)$ \\
\hline C & $3.49 \mathbf{b}$ & $17.52 \mathbf{b}$ & $113.23 \mathbf{n s}$ & $4.26 \mathbf{b}^{*}$ & $19.91 \mathbf{b}$ & $122.03 \mathbf{a b}$ \\
& $(0.93)$ & $(4.73)$ & $(24.12)$ & $(0.87)$ & $(3.89)$ & $(20.74)$ \\
\hline D & $3.14 \mathbf{b}$ & $15.78 \mathbf{b}$ & $110.90 \mathbf{n s}$ & $4.05 \mathbf{b}^{*}$ & $18.85 \mathbf{b}^{*}$ & $116.09 \mathbf{a}$ \\
& $(0.97)$ & $(4.46)$ & $(23.56)$ & $(0.85)$ & $(4.04)$ & $(25.62)$ \\
\hline
\end{tabular}

*Eşleştirilmiş t testi sonucunda hava kurusu ölçüm değerleri ile fark gösterenler $(\mathrm{p}<0.05)$

${ }^{1}$ Küçük harfler Duncan testi sonucunu göstermektedir.

Çizelge 2 incelendiğinde yonga levha içerisinde pirinç kavuzu kullanım oranının artmasına bağlı olarak tüm yüzey pürüzlülüğü parametrelerinin azalmış olduğu tespit edilmiştir. En yüksek yüzey pürüzlülük değerlerine kontrol grubu olarak belirlenen A grubunda rastlanırken (Ra: $4.45 \mathrm{Rz}: 21.18$ ve RSm: 120.10), en düşük sonuçlara yonga levhaların orta ve üst tabakalarında \% 30 oranına pirinç kavuzu kullanılarak üretilen deneme örneklerinde ulaşılmıştır (Ra: $3.14 \mathrm{Rz}: 15.78$ ve RSm: 110.90). Merkez çizgisi ortalama pürüzlülük değeri $(\mathrm{Ra})$ ele alındığında. Ra değerinin kontrol grubu olarak nitelendirilen A grubunda $4.45 \mu \mathrm{m}$, alt ve üst tabakalarda \% 30 pirinç kavuzu kullanılarak üretilen D grubunda ise $3.14 \mu \mathrm{m}$ olduğu görülebilecektir. Orta ve üst tabakalarda \%30 oranında pirinç kavuzu kullanımının Ra değerinde \%29.43 oranında bir azalma sağladığı tespit edilmiştir. Benzer durumu tüm yüzey pürüzlülügü parametrelerinde görmek mümkündür.

Çizelge 3.saat süre ile suda bekletilen yonga levhaların yüzey pürüzlülük değerlerinin hava kurusu yonga levhalara göre değişimi

\begin{tabular}{|c|c|c|c|}
\hline Yonga Levhalar & Ra (\%) & Rz (\%) & RSm (\%) \\
\hline A & 7.87 & 5.29 & 10.22 \\
\hline B & 17.96 & 11.15 & 8.17 \\
\hline C & 22.06 & 13.64 & 7.77 \\
\hline D & 28.98 & 19.46 & 4.68 \\
\hline
\end{tabular}


Çizelge 2'deki verilere göre 2 saat suda bekletilmiş yonga levhaların yüzey pürüzlülüğü değerlerinin hava kurusu yonga levhalardan daha yüksek olduğu görülmektedir. Çizelge 3 'te ise 2 saat süre ile suda bekletilmiş yonga levhaların yüzey pürüzlülük değerlerinin hava kurusu yonga levhaların yüzey pürüzlülük değerlerine göre yüzde değişim oranları görülmektedir. Suda bekletme işlemi Ra değerlerini A grubu yonga levhalarda \%7.87 oranında artırırken B grubu yonga levhalarda \%17.96 C grubu yonga levhalarda \%22.06 ve D grubu yonga levhalarda ise \% 28.98 oranında artırdığı gözlemlenmiştir. Rz değerleri için benzer eğilimden söz etmek mümkündür. Bu durum pirinç kavuzlarının katılım oranının artması ile yonga levhalardaki yüzey pürüzlülük değerlerinin genel olarak oransal olarak çok daha hızlı arttığını göstermektedir (Şekil 1).

Yine Çizelge 2'de ki Duncan testi sonuçları incelendiğinde sonuçların hava kurusu rutubet halindeki yonga levhalara ilişkin $\mathrm{Ra}$ ve $\mathrm{Rz}$ yüzey pürüzlülüğü parametrelerinde \% 0.05 hata payı ile anlamlı olduğu, RSm yüzey pürüzlülüğü parametresinde ise anlamsız olduğu tespit edilmiştir. Buna göre yonga levha içerisindeki pirinç kavuzu miktarı arttıkça hava kurusu haldeki Ra ve Rz yüzey pürüzlülüğü parametrelerinde $\% 0.05$ düzeyinde anlamlı sonuçlar elde edilmiştir. Yine aynı tablodan yonga levha içerisindeki pirinç kavuzu miktarı arttıkça 2 saat suda bekletme işlemi sonrasında yüzey pürüzlülügü parametrelerin tümünde \%0.05 önem düzeyinde anlamlı sonuçlar elde edildiği tespit edilmiştir. Çizelge 2'de ki eşleştirilmiş $\mathrm{t}$ testi sonuçlarına göre Ra değerinin $\mathrm{B}, \mathrm{C}$ ve $\mathrm{D}$ grubu yonga levhalarda. Rz değerinin ise $\mathrm{D}$ grubu yonga levhada 2 saat suda bekletme işlemi sonucunda anlamlı sonuçlar gösterdiği tespit edilmiştir.

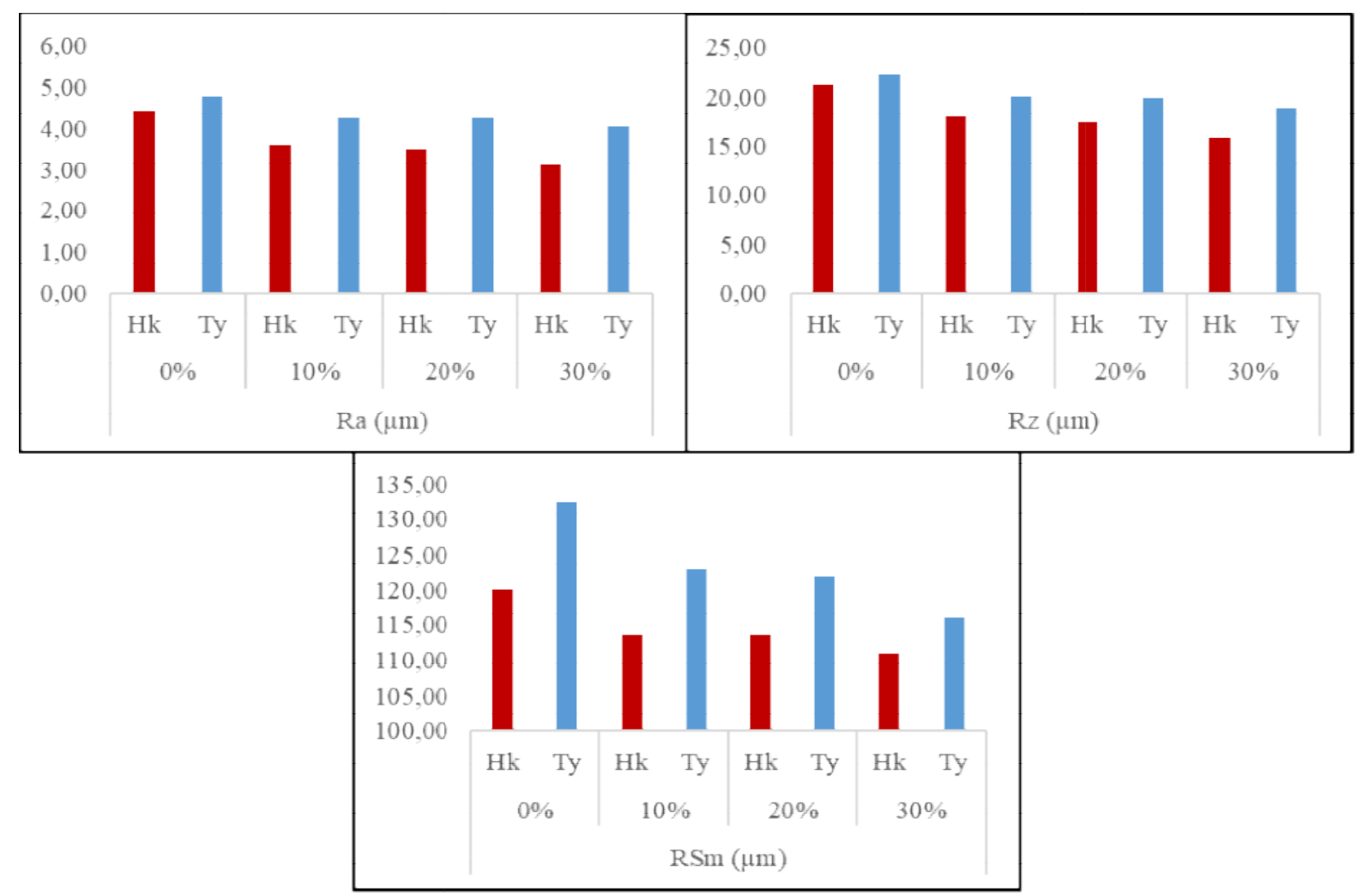

Şekil 1.Hava kurusu (Hk) ve 2 saat süre ile suda bekletilmiş (Ty) yonga levhaların yüzey pürüzlülük değerlerinin eşleştirilmiş t testi sonuçları 


\section{Sonuçlar ve Öneriler}

Pirinç kavuzlarının yonga levhaların yüzey pürüzlülüğü üzerine etkisi isimli bu çalışmada;

- Pirinç kavuzlarının yonga levha üretiminde kullanılmasının yüzey pürüzlülüğünü azalttığı tespit edilmiştir.

- Yonga levha içerisinde pirinç kavuzu kullanım oranının artmasına bağlı olarak tüm yüzey pürüzlülüğü parametrelerinin azalmış olduğu belirlenmiştir.

- 2 saat suda bekletme işleminin çeşitli oranlarda pirinç kavuzu kullanılarak üretilen yonga levhaların bazı yüzey pürüzlülüğü parametrelerinde anlamlı sonuçlar doğuracak bir artış sağladığı belirlenmiştir.

- Pirinç kavuzunun yonga levha endüstrisinde kullanımına ilişsin daha kapsamlı çalışmaların yapılması gerekmektedir. Pirinç kavuzunun yonga levha endüstrisinde kullanımının iktisadi analizinin yapılması gerekmektedir.

\section{Kaynaklar}

Akyüz. İ. (2004), Avrupa birliğine giriș sürecinde Türkiye ile Avrupa birliği üye ülkelerin yonga levha dış ticareti, Kafkas Üniversitesi, Artvin Orman Fakültesi Dergisi, 3 (4), 124-134.

Cooper, P.A., and Balatinecz, J.J. (1999), Agricultural waste materials for composites, centrefor management technology, Global Panel Based Conference (October 18-19), Kuala Lumpur, ML.

Çöpür, Y., Güler, C., Akgül, M., and Taşçığlu, C. (2007), Some chemical properties of hazelnut husk and its suitability for particle board production, Building and Environment, 42:2568-2572.

ISO 4287, (1997), Geometrical Product Specifications (GPS), Surface Texture: Profile Method, Terms, Definitions and Surface Texture Parameters, ISO.

Kayışoğlu. B., Tuğ. S., Dalmış, İ.S., Aktaş, T., Durgut, M.R., ve Durgut, F.T. (2016), Farklı katkı maddeleri kullanılarak hazırlanmış çeltik sapı peletlerinin gazlaştırılması, Tarım Makinaları Bilimi Dergisi, 12(1),37-44.

Liew, K.C., Ting, P.B.D., and Tan, Y.F. (2018), Physico-mechanical properties of particleboard made from seaweed adhesive and tapioca starch flour, Journal of theIndian Academy of Wood Science, 15(2),199-203.

Martins, E.H., Vilela. A.V., Mendesi R.F., Mendes, L.M., Vaz, L.E.V.S.B., and Junior, J.B.G. (2018), Soybean waste in particleboard production, Ciênciae Agrotecnologia, 42(2), 186-194.

Mengeloğlu, F. ve Alma, M.H. (2002), Buğday saplarının kompozit levha üretiminde kullanılması, KSÜ Fen ve Mühendislik Dergisi, 5(2), 37-48.

TS EN 325, (2014), Ahşap esaslı levhalar - deney parça boyutlarının tayini, TSE. Ankara.

Yavuz, G.G., Miran, B., Gürer, B.B., Yüksel, N.Y. ve Demir, A. (2016), Buğday,dane, mısır ve çeltik üretiminde fark ödemesi desteklerinin etkisi, Tarımsal Ekonomi ve Politika Geliştirme Enstitüsü (TEPGE), TEPGE Yayın No: 266. Ocak 2016. 